\title{
The Impact of the Specialist on Archives
}

This paper was delivered at the 1971 Program of the Law and Political Science Subsection of the Subject Specialist Section at the ALA Annual Conference, at Dallas, Texas.

\section{I}

F THERE IS ANY DOGMA in the archival profession, it is that one does not rearrange or otherwise disturb the natural order of the archival record. Although it is quite permissible, and even recommended, that disordered records be returned through rearrangement to their natural sequence, an archival code states that natural sequence is inviolate.

One must understand the reason for this dictum in order to comprehend the archivist's insistence on it in practice. The justification is that the creator of the record was a rational being, and had logical reasons for putting one document in a certain juxtaposition to another, and that the filing scheme itself could thus be used as a finding aid once the scheme was understood. This thesis occasionally holds true, and the incidence of truth increases in direct proportion to the size of the file and the organization that created it, because large records holders require good filing arrangements-a simple truism.

Archivists, then, have dwelt on this concept of "respect des fonds," or respect of original order, in accessioning and processing records holdings. And since the records are kept that way, they

Since June, 1968, Mr. Burke has been Director of Educational Programs at the National Archives and Records Service in Washington, D.C. should be described that way-that is, in their organic order. The description of records, therefore, is neither an index, since it is not an alphabetical listing or an item-by-item analysis, nor a calendar, since it is not a listing of all documents by date. Rather, it is an inventory, or a register.

Both terms are passive. One takes inventory of a warehouse, but the process does not affect the nature or arrangement of its contents. One registers deeds or legal instruments, merely accounting for them as they come, with no attributes imposed upon the material by the process. One may inventory records regardless of their order, and they are not rearranged to fit the inventory scheme. This is unlike cataloging a book, in which the process places the book in a scheme that is imposed upon it. Inventorying records merely recognizes their location in an inherited scheme.

Archivists in the federal government inventory by record group; usually a record group consists of the records of a bureau, or major large office within an agency. National Archives inventories, therefore, represent the vertical flow of bureau responsibilities, commonly known as a hierarchical format. Below the bureau are described its offices; within each office its departments; within each department its divisions, branches, and units. The inventory, therefore, is or 
should be an accurate description of the bureau's organization. Rarely does it reach perfection because of lacunae, and because organizational changes interrupt the time continuum of agency structure.

Inventories are but one reflection of an archivist's preoccupation with original order of records. In a major institution such as the National Archives, distribution of work responsibilities follows the same dictates as the arrangement of records. Archivists deal with specific agencies' records grouped according to some commonality. There are therefore, an Old Military Records Branch (pre1918), Modern Military Records Branch, an Industrial and Social Records Branch, a Legislative, Judicial, and Fiscal Records Branch, and so on. Characteristic of a large institution, there is a certain built-in isolation between branches.

As archivists react to researchers, they tend to think hierarchically and organizationally. A research question is immediately converted into which agency or bureau had the function, which divisions or branch of that bureau, and how the records are arranged.

Under these circumstances, one can easily understand why research in archives is a rather personalized activity. There is considerable intellectual contact between the archivist and the researcher. One cannot simply walk into an archives, nod at the staff members behind the service desk, go to the file of descriptive material, fill out a call slip, and sit back and wait for the records. Unfortunately, not many researchers understand this. This lack of understanding is not surprising since undergraduate students have little cause for, and no significant training in, the use of archival materials.

Such is not the case with libraries. My ten-year-old fourth-grader recently was asked literally to catalog a dozen books as part of a work assignment. The authors and titles of the books were given, with brief indications of whether or not they were fiction, biography, science, etc. In an opposite column were twelve Dewey decimal classification numbers, and her assignment was to match column A with column B. I was gratified when I looked over her finished work and found that she got all twelve right. She and her classmates can orient themselves in the school library and in the public library. They have learned to read the book and card catalogs. When they go to high school they may shift over, effortlessly, to the L.C. classification. By the time they get to college, and, perhaps on to graduate school, they will be able to walk into any library in the country, take a minute for orientation; and, after learning the floor plan and local idiosyncracies of the institution, go to work. However, if they step over into original source research in a major archive, they will be in trouble.

It is this never-never world of archives that deters young graduate students from taking the initial dip, and it is astounding how many reputable scholars, with significant bibliographies of their own, will admit, in a weak moment, to never having breached the formidable barrier of archival research. There is even a reluctance by many to enter an archives to initiate research, not because the process is so complex, but because the process is unknown to them, and the adult researcher does not wish to put himself in a prospectively embarrassing position by admitting to an archivist that he does not know the first thing about using archives.

Archivists, of course, are continually on the alert for this attitude, and attempt to assuage the researcher's fears with soothing counsel to the effect that he is not expected to know anything about archives. They are prepared to be friendly and to help him over the initial hump.

For this reason most archives and manuscript collections have an interview routine. The researcher initially talks with what one might call a superarchivist 


\section{4 / College \& Research Libraries • July 1972}

who knows something about the entire collection of materials and can direct him to the proper area and specialist archivist. The interviewer elicits from the researcher the bounds of his search, specifics he might be interested in, peripheral materials he is concerned with, and any other information helpful in determining the records to be used. In most cases, the interviewer then directs the researcher to an archivist who specializes in these records, and the interview process narrows until specific documents are identified. Once research has begun, there is further rapport between the researcher and the archivist responsible for the records.

There are still other basic differences between the use of an archives and the use of a library. One significant difference could be posited as the position of the staff between the researcher and his source. Both librarians and archivists act as the researcher's interpreters. In most instances the reference librarian stands between the researcher and the catalog, interpreting for the library user how to obtain information leading to his source. Once the user has been pointed in the proper direction through the catalog, the use and interpretation of printed matter is his private affair.

By the time a researcher gets to an archive, he may well have read all the descriptive literature in the form of record group inventories, since these are usually in printed brochure format and are available in many libraries around the country. At the archives, however, the archivist places himself between the researcher and the actual record, interpreting the user's needs in terms of the material itself-its arrangement, its relationship to other material, its internal finding aids (such as agency created indexes), and related matters (often even including historical significance). Very simply, it might be stated that the librarian is placed between the researcher and the finding aid, whereas the ar- chivist is between the finding aid and the records themselves.

There is another implication here. It is that the archivist, to be truly classified an archivist, must be a subject or an area specialist, with substantive knowledge of the content of the material for which he is responsible. His value is enhanced by the length of time he has worked with researchers in the records, and this experience results in a significant professional difference between librarians and archivists. A young law librarian at Washington University in St. Louis might have become very effective through her knowledge of the reference materials in her field, and the bibliographic corpus for a generalized law library. Should she be given an opportunity to assume a better paying position, for example, chief reference librarian at another general law library, she could make an advantageous professional move, and perform her duties at the new post with little trauma. On the other hand, an archivist, who has assumed some professional stature at the National Archives because of his intimate familiarity with the records of Department of Justice, would find it difficult if not impossible to transfer to another archival institution except in an administrative capacity. His professional strength would be weakened instead of reinforced, and a move to, let us say, the Texas State Archives would not permit him to use the knowledge he might have spent years developing. Except for some expertise in the use of storage boxes, the transferred archivist would be of little more value to Texas than a young, inexperienced one.

For this reason, there is little movement among archivists from institution to institution. Even within an institution there is little movement from one custodial division to another. This inevitably leads to a certain insularity of archivists that may not be true with librarians.

The picture drawn thus far, then, is 
of an institution containing unique documents of a highly detailed nature that, except in the case of genealogists, are rarely used below the advanced research level, or graduate-school level. To this institution come researchers who are untrained and inexperienced in the use of archival facilities. They find that records are kept, not according to any classification scheme, but in the order provided by the creating agency, and that overall the archives has arranged its material according to the structure and organization of the corporation or government whose records it holds. When the researcher seeks assistance, he is not confronted by a staff member who instructs him in the use of reference tools, points him in the right direction, and lets him go. Rather, he is met by one who presumes that he has a knowledge of the reference tools, leads him far beyond them into the very records themselves, hovers nearby available for further assistance should he loom up against the proverbial brick wall, and on occasion practically turns the pages and checks the indexes for the user.

Perhaps this summary illustrates that archival practice has been oriented toward the arrangement and description rather than the use of records. In the United States, really in the true tradition of major archives the world over, the arrangement, description, and preservation of public records has followed a practice of keeping them in an order reflecting government activities. This arrangement facilitates the search for specific information: a fact, report, or series of events that led to a policy decision or institution of a procedure. Archival arrangement facilitates pinpointing responsibility among government officials, and in many ways this is what archives are all about.

But this is not all that archives are about. Introduced to this highly formalized, hierarchical body of organized records is a conceptually oriented re- searcher, not interested in pinning down isolated facts, but devoted to exploring the broad range of a subject which he deems worthy of study. The metes and bounds of his subject may have no relationship to the organized structure of government. In fact, his interest in the government record may be only a small part of his study, which might also encompass periodical, monographic, and biographical literature, as well as personal papers and official archives. His concept, when superimposed on a body of records, may span a broad range of organizational divisions and time periods. For example, it is one thing to do archival research on the role of the Committee on Fair Employment Practice in World War II; it is quite another to enter the National Archives with a topic such as the social and economic condition of the Afro-American in the New Deal era. In the first case the researcher would receive a copy of Preliminary Inventory No. 147 for the Committee on Fair Employment Practice for Record Group 228. He would then consult the appropriate archivist in the Industrial and Social Records Branch, for help in using the files and suggestions for other sources of information.

A search for records relating to the social and economic condition of the Afro-American in the New Deal era would immediately create two problems. It is likely that New Deal era records would not refer to Afro-Americans in those terms, and it is improbable that agencies in the 1930s would have applied the term "New Deal" to themselves. Interpretation would therefore begin by changing terminology, and would proceed to analyzing federal activity in the field in the 1930s. Archivist and researcher would join in an effort to determine which federal agencies, both civilian and military, had active roles in Negro social and economic conditions. Probably a variety of agencies have dealt with labor, commerce, 
agriculture, the armed forces, health, welfare, education, and so on-in fact, one could envision almost every agency being involved in one way or another.

Considering the structuring of an archives as earlier noted, such a conceptual approach could cause the researcher considerable problems. He might want to look at almost all of the inventories of records contemporary with his project in order to assure himself that he is not missing anything. Then he might speak with archivists in most of the branches that he could receive the benefit of their cumulated knowledge. The task would be long and arduous, and under time pressures, the researcher might retreat to more easily used secondary and published documentary sources. This, then, is the question of "the impact of the specialist on archives."

The response to the specialist's needs may seem obvious, but it came about slowly in the archival world. It was to set up projects to analyze archival records in light of certain subject areas. The choice of where to start was not too difficult, because after many years of servicing records, the needs of researchers became apparent. But implementing subject guide projects was not as easy as deciding which ones should have priority. Again, the problem revolved around the need for highly qualified archivists to do the work. One cannot produce a guide to complex records with an untrained staff. The person most logically suited to cover a broad subject area is the senior professional with many years of work in his area of specialization. But because of retirements, shifts to administrative positions, and other natural reasons, such a person is not always on hand. Other considerations then impede.

Instead of producing a guide to records that have traditionally been heavily used, it is occasionally appropriate to anticipate heavy use far enough ahead to begin work on a guide based on future needs. Such a judgment would take an unnatural degree of prognostication on the part of the archivist were it not for the human habit of commemorating past events. Thus, in the 1950s one could assume that the period 1961-65 would produce an outpouring of research on the Civil War, so preparations were made for guides to records relating to the Civil War far enough in advance to answer the projected need. It takes no visionary to predict that a year or two from now historians, journalists, and others will turn to Revolutionary War themes in great numbers, so now is the time to begin work on a guide to records relating to the Revolution. A National Archives Civil War Guide was produced, in two volumes, and work is well underway toward the production of a Revolutionary War guide at the National Archives.

Other conditions, leading to the production of special guides, occasionally prevail. The mere existence of a senior staff member, extraordinarily knowledgeable about a subject or a record group may be sufficient reason to have him produce a special guide before he retires and his knowledge is lost to the researcher. Such was the case with the preparation of a first volume of the Guide to Materials on Latin America in the National Archives. We are far along on a guide to Alaskan material, and hope that it will be finished before the archivist in charge retires. We also have assigned an archivist and are now doing a research on a general guide to records relevant to Black history in the United States.

Thus, the subject specialist has caused the archivist to depart from his traditional descriptive role of inventorying records as they were created, and has led him to describe records, regardless of their sources, which fit a predetermined subject area. This is a step in the right direction for making archives easier to use for some, but it should be clear 
that it will never really answer the needs of the research community. Every day a researcher approaches the National Archives with a different conceptual framework into which he is trying to fit the records of the federal government. It is not possible to produce the variety of special guides needed to meet all of the scholar's requirements. It now takes anywhere from three to five years to prepare one special guide.

Some of us have been looking at archivists' methods for creating special guides, and we are becoming suspicious that there may be a better way, which would respond more to researcher needs. Just as one could computerize an entire library card catalog and then automatically search it for terms provided by the researcher-such as title, author, subject headings, and so on-so one could, theoretically, produce an archival data base containing all the tools the archivist now uses to manually produce a conceptual guide. By putting all known or published information about the records into the computer it would then be possible to query the data base through the use of terms relevant to the researcher's subject. These terms might number in the hundreds, and the researcher, who presumably has a better knowledge of his overall subject than the archivist does, should be able to supply the search terms.

This is not fantasy. We are following this procedure now, and have done so for many years. The only difference is that we are bound to a manual instead of an automated system. The archivist writing a guide peruses all of the published and unpublished finding aids, guides, indexes and other materials re- lating to the records. $\mathrm{He}$ has in mind a vast conglomeration of terms relevant to his search. When his mind registers a match in terms, he copies out the entry from the record and adds it to his growing list, which eventually will become the guide. If this menial automatic task can be consigned to a machine, the archivist will be free to sophisticate the search by looking at the actual record and checking out leads that the machine has fed him.

Archivists would then be in a position to render service to the subject specialist in accordance with his needs, rather than tailored to the archivist's work methods.

These halcyon days, needless to say, have not yet arrived. The technology is available, but other resources are not. There has been experimentation in these areas, and we are working toward such goals as the automated production of finding aids at the National Archives at the present time with some success, but on a small scale.

We would not be working on the problem at all if archives were as many theorists say they should be: merely repositories for the records of a corporate body, bastions of moldy antiquities used almost solely for analyzing or verifying activities and events of that corporate body. But the impact of the specialist researcher on archives has removed them from that category and transformed them into dynamic information centers. The challenge of the specialist is causing a minor upheaval among the archival theoreticians of this world, but the modern concept is emerging as the dominant one. It is in the wide dissemination of vast historical information that the future of archives lies. 